\title{
Evaluation of frequency of erythropoietin use among end stage renal disease patients in
} Quetta, Pakistan

\author{
Abdullah", Faria Khursheed, Sajjad Haider, Mohammad Younis \\ Faculty of Pharmacy \& Health Sciences, University of Balochistan, Quetta, PAKISTAN
}

Received: 02 January, 2020

Accepted: 17 March,2020

*Correspondence to: Mr. Abdullah,

Email:

abdullahniaz.uob@gmail.com

Copyright: (c) the author(s), publisher and licensee Indian Academy of Pharmacists. This is an open-access article distributed under the terms of the Creative Commons Attribution NonCommercial License, which permits unrestricted noncommercial use, distribution, and reproduction in any medium, provided the original work is properly cited.

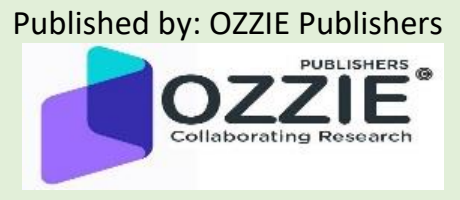

\section{Abstract}

Objective: While treating anaemia in end stage renal disease (ESRD) patients, recombinant human erythropoietin (EpO) is the therapy of choice. However, it is rarely used in developing countries because of the financial constrains to the healthcare as well as the patient. Keeping the point of view in mind, the objective of this research was to identify the use of Epo, its frequency, and dosage in the patients of ESRD receiving continuous haemodialysis in Quetta city, Pakistan. Methods: This was a retrospective, single cantered study. The selected population was subject with ESRD and on dialysis with prolonged anaemia. All recipients of dialysis in the past one year were targeted for the study. Data of the patients regarding anaemia and the use of erythropoietin was collected through a data collection sheet. Evaluation of the bio-chemical parameters of ESRD patients on haemodialysis was also be taken into consideration. Demographics of the selected patients were recorded carefully for the evaluation and analysis. SPSS 20.0 was used for data analysis and based on the objectives; both descriptive and inferential statistics were used for data elaboration. Results: A total of 97 ESRD patients that fulfilled the inclusion criteria were enrolled. Out of the $97,(52.6 \%)$ had age of more than 47 years and the cohort was dominated by males $(63,64.9 \%)$. Seventy two patients were on EPo use with majority on dose of 10000 IU with once a week frequency. The Man Whitney U test was used to compare erythropoietin use / non use and biochemical parameters. Haemoglobin percentage was significantly associated with erythropoietin use $(\mathrm{p}<0.05)$. The mean rank interpretation revealed erythropoietin users significantly associated with improved haemoglobin percentage. The Kruskal Wallis test was used to compare erythropoietin usage frequency and biochemical parameters. Haemoglobin percentage was again significantly associated with erythropoietin use frequency. The Bonferroni correction revealed erythropoietin frequency of twice a week was significantly associated with improved haemoglobin percentage. Conclusion: Although the use of EPO among ESRD was reasonable, few patients were not prescribed EPo for anaemia associated with ESRD. We do understand that availability and affordability can be a major reason here; policy makers should make sure about the use of EPo because of its evidence-based advantages over other procedures.

Keywords: Frequency, erythropoietin, end stage renal disease, Quetta

\section{INTRODUCTION}

Anaemia is one of an important complications of End Stage Renal Disease (ESRD). ${ }^{[1]}$ The condition is coupled with deprived survival in persons who have complex and continual kidney ailments. Such patients ate therefore recommended to undergo continuation of dialysis procedures. ${ }^{[1]}$ In terms of treatment rationality, the foremost intention of the dialysis procedure targets to increase patients' continued survival, decreasing the morbidity rates and humanizing the overall Quality of Life (QOL). ${ }^{[2]}$ Nevertheless, this does not happen in real time practice as regardless of technological improvements of pharmaceutical care, high rates of mortality and morbidity and poor QOL of dialysis patients is reported in literature. ${ }^{[3]}$ Quality of Life in ESRD patients is recovered at higher haematocrit levels. ${ }^{[4]}$ Within this context, severe anaemia is a major confine to psychoanalysis in patients with ESRD. ${ }^{[1]}$ Preceding approximation of storage iron in patients with dialysis linked anaemia reported that that unprocessed haemodialysis patients experience total iron insufficiency of roughly $1 \mathrm{mg}$ per day during dialyzer and blood loss. ${ }^{[5]}$ Inline to what is reported in literature, the identified pathogenetic factor causing anaemia in ESRD population is the reduced production of erythropoietin in the diseased kidneys. ${ }^{[6,7]}$

While treating ESRD and anaemia as an associated disorder, recombinant human erythropoietin (EpO) is the therapy of choice for the last ten years. ${ }^{[8-10]}$ Conversely, previous to the accessibility of epoetin, the stronghold of anaemia treatment in ESRD was blood transfusions. ${ }^{[11,12]}$ Erythropoietin is advanced when compared with blood transfusions as it has fewer undesirable reactions. Furthermore, epoetin is the reason of fabrication and discharge of young blood cells via bone marrow into systemic circulation. ${ }^{[13,14]}$ The Health-Related Quality of Life (HRQoL) also exhibits the usefulness of epoetin remedy when managed as a usual clinical 
procedure. ${ }^{[15]}$ When related to ESRD, the K/DOQI guiding principles advocate that the haemoglobin levels should stay at 11 - $12 \mathrm{~g} / \mathrm{dL} .{ }^{[16]}$ Therefore, patients treated with oral iron therapy demonstrate affirmative iron balance hence confirming that bowel iron assimilation is not disturbed in ESRD patients undergoing dialysis. ${ }^{[16]}$ The valuable outcome of stabilizing the haematocrit levels in ESRD is positively linked to advancement observed in both cognitive and corporeal functions and an improved QOL. ${ }^{[2]}$ Therefore based on the recommendations of the guidelines, it is hypothesized that a good level of haematocrit balance maintains the quality of life among dialysis patients.

Shifting our concerns to conditions in a developing country like Pakistan, Pakistan is one of the largest and most populous countries of the South Asian region. Among multiple concerns, a great apprehension for the healthcare system today is the increased frequency of NCDs including chronic kidney disease or end-stage kidney disease thus resulting in an increase of haemodialysis recipients in recent years. In Pakistan, around 20 million people are suffering from kidney diseases and nearly 16,000 new cases of kidney failure are registered. ${ }^{[17]}$ Furthermore, $40-50$ percent of the patients are not surgically fit for transplantation, while only 15 percent donate their kidneys to relatives. ${ }^{[17]}$ This ultimately results in the increased frequency of haemodialysis across the country as there is no other treatment option available for kidney patients in Pakistan. Even at the treatment level, compounds like erythropoietin are rarely used because of the financial constrains to the healthcare as well as the patient. Consequently, this imposes a huge financial, economical and societal burden on the deprived healthcare system as the conditions worsen and there is no choice of treatment available. Therefore, it is wise to initiate rational treatment in the initial stages so that the complications of ESRD can be minimized later. Keeping the point of view in mind, the objective of this research was to identify the use of Epo, its frequency, and dosage in the patients of ESRD receiving continuous haemodialysis in Quetta city, Pakistan. We also aimed that the results of the study will urge the physicians to start using erythropoietin early in the treatment plans so that the patients can get maximum benefits of the therapeutic plans.

\section{METHODS}

\section{Study design and settings}

This was a retrospective, single cantered study. The research was carried out at Baluchistan institute Of Nephrology and Urology Quetta (BINUQ). BINUQ was established in November 2006 for kidney related diseases. It is a wellequipped institute with all modern treatment facilities, providing care for patients in the field of urology and nephrology. A twelve bedded well equipped haemodialysis unit provides services in three shifts and an extension program of haemodialysis unit is almost near completion. This added program will enable the institute to become a 40 bedded haemodialysis unit to facilitate the increasing number of haemodialysis patients.

\section{Study population, sampling and inclusion criteria}

The selected population was subject with ESRD and on dialysis with prolonged anaemia. All recipients of dialysis in the past one year (2019) and attending the above mentioned healthcare facilities were targeted for the study. Patients having ESRD \& congestive heart failure on dialysis, receiving any surgical intervention or receiving renal transplant were excluded from the study.

\section{Data collection and analysis}

Data of the patients regarding anaemia and the use of erythropoietin was collected through a standardized data collection sheet. Evaluation of the biochemical parameters of ESRD patients on haemodialysis was also be taken into consideration. The use of erythropoietin and other hematinic ratios, frequency and dosage were recorded and analysed. Demographics of the selected patients were recorded carefully for the evaluation and analysis. SPSS 20.0 was used for data analysis and based on the objectives; both descriptive and inferential statistics were used for data elaboration.

\section{Ethical approach}

Ethical approval was taken from Faculty of Pharmacy \& Health Sciences, University of Balochistan Quetta. Additionally, permission from the Executive Director of BINUQ was also taken before data collection.

\section{RESULTS}

\section{Demographic characteristics of the study respondents}

The demographic information of the study respondents is presented in Table 1. A total of 97 ESRD patients that fulfilled the inclusion criteria were enrolled. Out of the 97, $(52.6 \%)$ had age of more than 47 years and the cohort was dominated by males $(63,64.9 \%)$. Seventy two patients were on EPo use with majority on dose of 10000 IU with once a week frequency.

Table 1: Demographic characteristics of the study respondents

\begin{tabular}{|c|c|c|}
\hline Characteristics & Frequency & Percentage \\
\hline \multicolumn{3}{|l|}{ Age } \\
\hline $18-27$ & 19 & 19.6 \\
\hline $28-37$ & 10 & 10.3 \\
\hline $38-47$ & 17 & 17.5 \\
\hline$>47$ & 51 & 52.6 \\
\hline \multicolumn{3}{|l|}{ Gender } \\
\hline Male & 63 & 64.9 \\
\hline Female & 34 & 35.1 \\
\hline \multicolumn{3}{|c|}{ Use of Erythropoietin } \\
\hline Yes & 72 & 74.2 \\
\hline No & 25 & 25.8 \\
\hline \multicolumn{3}{|c|}{ Dose of Erythropoietin (IU) } \\
\hline 0 & 25 & 27.8 \\
\hline 5000 & 4 & 2.1 \\
\hline 10000 & 68 & 70.1 \\
\hline \multicolumn{3}{|c|}{ Frequency of Erythropoietin Use } \\
\hline Once/Week & 62 & 63.9 \\
\hline Twice/Week & 12 & 8.2 \\
\hline None & 25 & 27.8 \\
\hline
\end{tabular}

Haemodialysis and blood transfusion related information of the study respondents

Out of the 97 patients, eighty six percent were on haemodialysis with a frequency of twice a week. Majority of the respondents were on arteriovenous access while 58 $(59.8 \%)$ were on blood transfusion as shown in Table 2. 
Table 2: Haemodialysis and blood transfusion related information of the study respondents

\begin{tabular}{|c|c|c|}
\hline Characteristics & Frequency & Percentage \\
\hline \multicolumn{3}{|c|}{ Frequency of Haemodialysis } \\
\hline Once per week & 11 & 11.3 \\
\hline Twice per week & 84 & 86.6 \\
\hline Thrice per week & 2 & 2.1 \\
\hline \multicolumn{3}{|c|}{ Duration of Haemodialysis } \\
\hline 1-12 months & 64 & 65.9 \\
\hline $1-3$ years & 8 & 8.2 \\
\hline$>3$ years & 25 & 25.7 \\
\hline \multicolumn{3}{|l|}{ Vascular Access } \\
\hline Subclavian & 9 & 9.3 \\
\hline Arteriovenous & 88 & 90.7 \\
\hline \multicolumn{3}{|l|}{ Blood Transfusion } \\
\hline Yes & 58 & 59.8 \\
\hline No & 39 & 40.2 \\
\hline \multicolumn{3}{|c|}{$\begin{array}{l}\text { Frequency of Blood } \\
\text { Transfusion }\end{array}$} \\
\hline Once per week & 11 & 18.9 \\
\hline Twice per week & 23 & 39.6 \\
\hline Once in 2 Weeks & 6 & 10.3 \\
\hline Once in 3 Weeks & 6 & 10.3 \\
\hline Once in a month & 12 & 20.6 \\
\hline
\end{tabular}

Comorbid and bio-chemical information of the study respondents

Twenty (20.6\%), $31(32.0 \%)$ and $5(5.2 \%)$, of the respondents were positive for Hepatitis-B, Hepatitis-C and HIV respectively. All patients were hypertensive while 77 (79.4\%) had Type II diabetes mellitus. The mean values of biochemical parameters were assessed and are presented in Table 3 .

Table 3: Comorbid and bio-chemical information of the study respondents

\begin{tabular}{|c|c|c|}
\hline $\begin{array}{l}\text { Disease related } \\
\text { characteristics }\end{array}$ & Frequency & Percentage \\
\hline \multicolumn{3}{|l|}{ HbsAg } \\
\hline Positive & 20 & 20.6 \\
\hline Negative & 77 & 79.4 \\
\hline \multicolumn{3}{|l|}{$\mathrm{HCV}$} \\
\hline Positive & 31 & 32.0 \\
\hline Negative & 66 & 68.0 \\
\hline \multicolumn{3}{|l|}{$\mathrm{HIV}$} \\
\hline Positive & 5 & 5.2 \\
\hline Negative & 92 & 94.8 \\
\hline \multicolumn{3}{|l|}{ Diabetes } \\
\hline Type II Diabetic & 77 & 79.4 \\
\hline Type-I Diabetic & 2 & 2.06 \\
\hline Non Diabetic & 20 & 20.6 \\
\hline \multicolumn{3}{|l|}{ Hypertension } \\
\hline Yes & 97 & 100.00 \\
\hline Biochemical parameters & \multicolumn{2}{|c|}{ mean \pm sd } \\
\hline Haemoglobin \%age (mg/dl) & \multicolumn{2}{|c|}{$9.05 \pm 1.47$} \\
\hline Serum Urea $(\mathrm{mg} / \mathrm{dl})$ & \multicolumn{2}{|c|}{$70.61 \pm 45.72$} \\
\hline Urea creatinine $(\mathrm{mg} / \mathrm{dl})$ & \multicolumn{2}{|c|}{$7.87 \pm 2.55$} \\
\hline Serum Calcium $(\mathrm{mg} / \mathrm{dl})$ & \multicolumn{2}{|c|}{$7.68 \pm 1.85$} \\
\hline Serum Sodium $(\mathrm{mmol} / \mathrm{l})$ & \multicolumn{2}{|c|}{$139.81 \pm 15.34$} \\
\hline Serum Chloride (mmol/l) & \multicolumn{2}{|c|}{$116.16 \pm 10.60$} \\
\hline Serum Potassium $(\mathrm{mmol} / \mathrm{l})$ & \multicolumn{2}{|c|}{$5.54 \pm 0.91$} \\
\hline
\end{tabular}

\begin{tabular}{|l|c|}
\hline Fasting Blood Sugar $(\mathrm{mg} / \mathrm{dl})$ & $147.01 \pm 24.66$ \\
\hline $\begin{array}{l}\text { Systolic blood pressure } \\
(\mathrm{mm} / \mathrm{Hg})\end{array}$ & $86.91 \pm 16.63$ \\
\hline $\begin{array}{l}\text { Diastolic blood pressure } \\
(\mathrm{mm} / \mathrm{Hg})\end{array}$ & $129.79 \pm 47.41$ \\
\hline
\end{tabular}

Inter group comparison (erythropoietin use) and study parameters

The Man Whitney U test was used to compare erythropoietin use / non-use and biochemical parameters. Haemoglobin percentage was significantly associated with erythropoietin use. The mean rank interpretation revealed erythropoietin users significantly associated with improved haemoglobin percentage. No significant association was found among other study variables as shown in Table 4.

Table 4: Inter group comparison (erythropoietin use) and study parameters

\begin{tabular}{|l|c|}
\hline \multicolumn{1}{|c|}{ Biochemical parameters } & $\begin{array}{c}\text { P-Value (compared } \\
\text { with erythropoietin and } \\
\text { non use)* }\end{array}$ \\
\hline Systolic Blood Pressure & 0.612 \\
\hline Diastolic Blood Pressure & 0.707 \\
\hline Fasting Blood Sugar $(\mathrm{mg} / \mathrm{dl})$ & 0.099 \\
\hline Serum Urea $(\mathrm{mg} / \mathrm{dl})$ & 0.038 \\
\hline Blood Sugar $(\mathrm{mg} /$ & 0.626 \\
\hline Serum Calcium $(\mathrm{mg} /$ & 0.984 \\
\hline Serum Sodium $(\mathrm{mmol} / \mathrm{l})$ & 0.533 \\
\hline Serum Chloride $(\mathrm{mmol} / \mathrm{l})$ & 0.653 \\
\hline Serum Potassium $(\mathrm{mmol} / \mathrm{l})$ & 0.423 \\
\hline Hb \%age $(\mathrm{mg} / \mathrm{dl})$ & $\mathbf{0 . 0 0 8}$ \\
\hline
\end{tabular}

Inter group comparison (erythropoietin frequency) and study parameters

The Kruskal Wallis test was used to compare erythropoietin usage frequency and biochemical parameters. Haemoglobin percentage was again significantly associated with erythropoietin use frequency. The Bonferroni correction revealed erythropoietin frequency of twice a week was significantly associated with improved haemoglobin percentage. No significant association was found among other study variables as shown in Table 5.

Table 5: Inter group comparison (erythropoietin frequency) and study parameters

\begin{tabular}{|l|c|}
\hline \multicolumn{1}{|c|}{ Biochemical parameters } & $\begin{array}{c}\text { P-Value (frequency of } \\
\text { erythropoietin use)* }\end{array}$ \\
\hline Systolic Blood Pressure & 0.450 \\
\hline Diastolic Blood Pressure & 0.231 \\
\hline Diabetes & 0.955 \\
\hline Serum Urea (mg/dl) & 0.550 \\
\hline Blood Sugar (mg/ & 0.211 \\
\hline Serum Calcium (mg/ & 0.099 \\
\hline Serum Sodium $(\mathrm{mmol} / \mathrm{l})$ & 0.488 \\
\hline Serum Chloride $(\mathrm{mmol} / \mathrm{l})$ & 0.560 \\
\hline Serum Potassium $(\mathrm{mmol} / \mathrm{l})$ & 0.309 \\
\hline Hb \%age $(\mathrm{mg} / \mathrm{dl})$ & $\mathbf{0 . 0 0 1}$ \\
\hline
\end{tabular}

\section{DISCUSSION}

Erythropoietin was introduced in clinical practice in late 1980 's and since then it is considered as a standard of care for the treatment of anaemia in patients with chronic kidney disease. ${ }^{[18]}$ The extensive use of Epo and its analogues for the 
purpose of anaemia correction has succeeded in improving functionality, cognitive performance and overall quality of life. ${ }^{[18]}$ However, the use of Epo from the developing countries like Pakistan is least reported. Therefore, the current study was aimed to evaluate the frequency of erythropoietin use among end stage renal disease patients in Quetta city, Pakistan.

Results of the current study reported that EPo was used among $72(74.2 \%)$ of the patients while majority $(70.1 \%)$ were administered with a dose of 10,000 IU. Although majority of the patients were administered EPo weekly, 12 (8.2\%) of the patients were administered with EPo with a twice a week regimen. Within this context, even though the benefits of EPo administration in dialysis patients is well established, the best possible frequency schedule has not as yet been established. On the other hand, treatment with EPo is expensive and there is therefore a need for optimizing the effectiveness of its administration in patients with ESRD. ${ }^{[19]}$ Streja et al reported the relationship between the received dose of EPo and mortality in dialysis patients. The authors presented a positive dose-response relationship between weekly dose of EPo and the risk of death and higher dose of EPo was associated with increased mortality. ${ }^{[20]}$ Therefore, the scientific guidelines suggest modifying the partial haemoglobin levels in dialysis patients by EPo but it is not recommended obtaining the same haemoglobin level as the healthy people's standard levels in these patients. ${ }^{[21]}$ Connecting the observations with the current study results, the mean haemoglobin $(\mathrm{Hb})$ percentage reported was 9.05 which is less than the normal ranges. Therefore, as per what is reported by Drüeke et al, pracitioners at the hospital should reconsider the dose adjustment in patients with ESRD in the current cohort as higher doses are related to dose related complications.

Based on the literature review and as expected, the use and frequency of EPo use was significantly associated with $\mathrm{Hg}$ percentages. Our study findings are also evident from the literature as Panjeta and colleagues reported the same relationships between EPo use and $\mathrm{Hb}$ percentages. ${ }^{[22]}$ Inline to what is reported earlier; the direct relationship was also reported is a study of the same nature. ${ }^{[23]}$ Therefore, the use of EPo as reported earlier is recommended in patients with ESRD. The only limitation with the use of EPo is the cost as EPo is relatively expensive and it is not always the treatment of choice for the developing healthcare systems. Furthermore, during the study it was also discussed that the availability of EPo in the said hospital is also an issue at certain periods of the year. Therefore, until or unless the EPo is available, it is used for patients with anaemia associated ESRD. Therefore, we do urge the practitioners in healthcare settings to focus on the use and regular availability of EPo at the healthcare centres as human EPo corrects anaemia and reduces the chances of blood transfusions. ${ }^{[24]}$

Haemoglobin percentage was again significantly associated with erythropoietin use frequency. The Bonferroni correction revealed erythropoietin frequency of twice a week was significantly associated with improved haemoglobin percentage. It is obvious that the more EPo is administered the more are the chances of $\mathrm{Hb}$ increase. ${ }^{[25]}$ However, the presence of other predisposing factors, condition and stage of the kidney and other pathological conditions are not to be neglected. As mentioned earlier, the dosage of EPo should be thought of as there is no clinical evidence supporting higher doses of EPo use in ESRD patients. Even though the percentage of twice a week administration is very few in our study cohort, twice administration of EPo should be avoided and other measures should be applied to increase $\mathrm{Hb}$ where feasible and are available.

\section{CONCLUSION}

Although the use of EPO among ESRD was fairly reasonable, few patients were not prescribed EPo for anaemia associated with ESRD. We do understand that availability and affordability can be a major reason here; policy makers should make sure about the use of EPo because of its evidence-based advantages over other procedures. Additionally, the dose of EPo and the rise in $\mathrm{Hb}$ should be monitored very carefully so that a change in dose can be recommended that can provide maximum therapeutic effect among patients with ESRD.

\section{DISCLOSURE}

The authors have no conflict of interest to disclose. No funding was received for the study.

\section{REFERENCES}

1. Fishbane S, Spinowitz B. Update on anaemia in ESRD and earlier stages of CKD: core curriculum 2018. Am J Kidney Dis. 2018; 71(3): 423-35.

2. Cruz MC, Andrade C, Urrutia M, Draibe S, NogueiraMartins LA, Sesso RdCC. Quality of life in patients with chronic kidney disease. Clinics. 2011; 66(6): 991-5.

3. Morsch CM, Gonçalves LF, Barros E. Health-related quality of life among haemodialysis patients-relationship with clinical indicators, morbidity and mortality. J Clin Nurs. 2006; 15(4): 498-504.

4. Lee S-Y, Lee H-J, Kim Y-K, et al. Neurocognitive function and quality of life in relation to hematocrit levels in chronic hemodialysis patients. J Psychosom Res. 2004; 57(1): 510.

5. Rivera SM, Diversi K. DASH Diet for Renal Health: A Customized Program to Improve Your Kidney Function based on America's Top Rated Diet: Ulysses Press; 2018.

6. Webster AC, Nagler EV, Morton RL, Masson P. Chronic kidney disease. The Lancet. 2017; 389(10075): 1238-52.

7. Weiss G, Goodnough LT. Anaemia of chronic disease. N Engl J Med. 2005; 352(10): 1011-23.

8. Jungers P, Choukroun G, Oualim Z, Robino C, Nguyen AT, Man NK. Beneficial influence of recombinant human erythropoietin therapy on the rate of progression of chronic renal failure in predialysis patients. Nephrol Dial Transplant. 2001; 16(2): 307-12.

9. Corwin HL, Gettinger A, Pearl RG, et al. Efficacy of recombinant human erythropoietin in critically ill patients: a randomized controlled trial. JAMA. 2002; 288(22): 2827-35.

10. Fishbane S, Berns JS. Hemoglobin cycling in hemodialysis patients treated with recombinant human erythropoietin. Kidney Int. 2005; 68(3): 1337-43.

11. Babitt JL, Lin HY. Mechanisms of anaemia in CKD. Journal of the American Society of Nephrology. 2012; 23(10): 1631-4.

12. Tanhehco YC, Berns JS, editors. Red Blood Cell Transfusion Risks in Patients with End-Stage Renal Disease. Seminars in dialysis; 2012: Wiley Online Library.

13. Gobe GC, Endre ZH, Johnson DW. Administration of erythropoietin and its derivatives in renal disease: 
advantages, mechanisms and concerns. Drug Discov Today Ther Strateg. 2007; 4(1): 79-84.

14. van Iperen CE, Gaillard CA, Kraaijenhagen RJ, Braam BG, Marx JJ, van de Wiel A. Response of erythropoiesis and iron metabolism to recombinant human erythropoietin in intensive care unit patients. Crit Care Med. 2000; 28(8): 2773-8.

15. Unruh ML, Weisbord SD, Kimmel PL, editors. Psychosocial factors in patients with chronic kidney disease: Health-related quality of life in nephrology research and clinical practice. Seminars in dialysis; 2005: Wiley Online Library.

16. Levey AS, Coresh J, Bolton K, et al. K/DOQI clinical practice guidelines for chronic kidney disease: evaluation, classification, and stratification. Am J Kidney Dis. 2002; 39(2 SUPPL. 1):

17. Staff reporter. $20 \mathrm{~m}$ facing kidney disease in Pakistan. The Nation. 2017.

18. Kalantar-Zadeh K. History of erythropoiesis-stimulating agents, the development of biosimilars, and the future of anaemia treatment in nephrology. Am J Nephrol. 2017; 45(3): 235-47.

19. Cody JD, Daly C, Campbell MK, et al. Frequency of administration of recombinant human erythropoietin for anaemia of end-stage renal disease in dialysis patients. Cochrane Database Syst Rev. 2005; (4):CD003895.

20. Streja E, Park J, Chan T-Y, et al. Erythropoietin dose and mortality in hemodialysis patients: marginal structural model to examine causality. Int J Nephrol. 2016; 2016(8): 6087134.

21. Drüeke TB, Locatelli F, Clyne N, et al. Normalization of hemoglobin level in patients with chronic kidney disease and anaemia. N Engl J Med. 2006; 355(20): 2071-84.

22. Panjeta M, Tahirovic I, Karamehic J, Sofic E, Ridic O, Coric J. The relation of erythropoietin towards hemoglobin and hematocrit in varying degrees of renal insufficiency. Mater Sociomed. 2015; 27(3): 144.

23. Parfrey PS. Target hemoglobin level for EPO therapy in CKD. Am J Kidney Dis. 2006; 47(1): 171-3.

24. Fishbane $S$. Recombinant human erythropoietin decreases the need for blood transfusions and may delay dialysis in chronic renal failure. ACP JvClub. 2002; 136(3):85.

25. Ng T, Marx G, Littlewood T, Macdougall I. Recombinant erythropoietin in clinical practice. Postgrad Med J. 2003; 79(933): 367-76.

Cite article as: Abdullah, Khursheed F, Haider S, Younis M. Evaluation of frequency of erythropoietin use among end stage renal disease patients in Quetta, Pakistan. Res Pharm Healt Sci. 2020;6(1):103-107. https://doi.org/10.32463/RPHS.2020.v06i01.02 